\title{
COMPREENSÕES DE PESQUISADORES DA ÁREA DE ENSINO DE FÍSICA SOBRE A TEMÁTICA AMBIENTAL E AS SUAS ARTICULAC̣ÕES COM 0 PROCESSO EDUCATIVO
}

\author{
Luciano Fernandes Silva* \\ Mariana Feiteiro Cavalari** \\ Cristiane Muenchen ${ }^{* *}$
}

RESUMO: Neste trabalho foram investigadas as compreensões sobre a temática ambiental e as suas articulações com o processo educativo presentes nos artigos divulgados nas atas dos Encontros de Pesquisa em Ensino de Física, realizados entre os anos de 2000 e 2012. A partir de procedimentos analíticos do campo da Análise de Conteúdo, percebeu-se que esses trabalhos apresentam um posicionamento crítico no que se refere à relação sociedadenatureza, sobretudo ao associá-la a aspectos como complexidade, incertezas, controvérsias e críticas ao sistema econômico vigente. Em relação ao processo educativo, alguns trabalhos articularam o campo do Ensino de Física com o da Educação Ambiental e outros articularam o enfoque CTS/CTSA com discussões relativas à temática ambiental e ao Ensino de Física.

Palavras-chave: Temática ambiental. Processo educativo. Ensino de Física.

\section{THE RESEARCHERS' UNDERSTANDING IN PHYSICS TEACHING ON THE ENVIRONMENTAL THEMES AND ITS ARTICULATIONS WITH THE TEACHING PROCESS}

ABSTRACT: This paper investigates the understanding of environment thematic and its articulations with the teaching process present in the articles published on the proceedings of the Encontro de Pesquisa em Ensino de Física (Physics Teaching Research Summits) from 2000 to 2012. By Content Analysis' analytical procedures, it was discovered that those works take critical stands as far as the relationship between society and nature is taken into account, mainly as this relationship is associated to aspects such as complexity, uncertainty, controversy and critics to the present economic system. Regarding the educative process, some works make a relation between the field of Physics teaching and Environmental Education, whereas others articulate the focus environment-technology-society (STS) with discussions on environmental themes and Physics teaching.

KEYWORDS: Environmental Themes. Educative Process. Physics Teaching.

\footnotetext{
* Doutor em Educacãa pela Universidade Estadual Paulista (UNESP) de Araraquara. Professor do Instituto de Física e Química e dos Programas de Pós-Graduação em Ensino de Ciência da Universidade Federal de Itajubá (UNIFEI) e dos Programas de Pós-Graduação em Educação da Universidade Estadual Paulista (UNESP) de Rio Claro, SP Brasil.

E-mail: lufesilv@gmail.com.

* * Doutora em Educação Matemática pela Universidade Estadual Paulista (UNESP) de Rio Claro. Professora do Instituto de Matemática e Computação e Programa de Pós-Graduaçã́o em Ensino de Ciências da Universidade Federal de Itajubá (UNIFEI, Itajubá, MG, Brasil).

E-mail:mafeiteiro@yahoo.com.br.

*** Doutora em Educação Científica e Tecnológica pela Universidade Federal de Santa Catarina (UFSC).

Professora do Departamento de Física e dos Programas de Pós-Graduacão em: Educação em Ciências Química da Vida e Saúde e Educação Matemática e Ensino de Física da Universidade Federal de Santa Maria, Santa Maria, RS, Brasil.

E-mail: crismuenchen@yahoo.com.br.
} 
COMPRENSIONES DE INVESTIGADORES EN ENSEÑANZA DE FÍSICA ACERCA DE LA TEMÁTICA AMBIENTAL Y SUS ARTICULACIONES CON EL PROCESO EDUCATIVO

RESUMEN: En este trabajo, fueron investigadas las comprensiones acerca de la temática ambiental y sus articulaciones con el proceso creativo presentes en los artículos publicados en las atas de los Encontros de Pesquisa em Ensino de Física (Encuentros de Investigación de Enseñanza de la Física), realizados entre los años 2000 y 2012. A partir de procedimientos analíticos del campo del Análisis de Contenido, se percibió que eses trabajos presentan un posicionamiento crítico referente a la relación sociedad-naturaleza, especialmente al asociarlas a aspectos como complexidad, incertidumbres, controversias y críticas al sistema económico vigente. En relación al proceso educativo, algunos trabajos articularon el campo de la Enseñanza de la Física con el de la Educación Ambiental y otros articularon el enfoque CTS/CTSA con discusiones relativas a la temática ambiental y la Enseñanza de la Física.

Palabras clave: Temática ambiental. Proceso Educativo. Enseñanza de la Física 


\section{INTRODUÇÃO}

Os níveis de degradação ambiental experimentados por diferentes sociedades ao redor do mundo, sobretudo após a segunda metade do século XX, têm chamado a atenção de diversos grupos sociais organizados, incluindo a comunidade científica. Destaca-se que estes produzem uma polissemia de discursos sobre a temática ambiental, frequentemente relacionados às origens, às causas e aos efeitos dessas degradações.

O conteúdo presente nesses discursos indica as concepções que os sujeitos possuem sobre a temática ambiental e, muitas vezes, explicita interesses econômicos e políticos que estão em jogo na sociedade. Esses conteúdos podem ser organizados e classificados em algumas categorias de análise. Moraes (2002), por exemplo, ao analisar as diferentes concepções dos cientistas sociais sobre a temática ambiental, cunhou os termos tecnicista, naturalista e romântico.

Na perspectiva tecnicista, o núcleo os discursos sobre a temática ambiental é a defesa da ideia de que as decisões importantes da sociedade devem ser tomadas por um corpo técnico qualificado. Nesse caso, aponta-se que os problemas ambientais devem ser administrados tecnicamente por especialistas, sobretudo porque estes possuem condições privilegiadas para escolher, com neutralidade, os processos técnicos que amenizam com eficiência os efeitos das degradações ambientais. Concepções dessa natureza secundarizam a dimensão social da temática ambiental, como se as soluções técnicas não envolvessem decisões políticas, interesses, projetos e perspectivas conflitantes. O discurso pautado pelo tecnicismo objetiva autonomizar a Ciência em relação à sociedade que a gerou, pondo a técnica como algo acima dos conflitos e das disputas. A perspectiva tecnicista leva a entender que a Ciência e a Tecnologia são as únicas alternativas viáveis para a superação dos problemas ambientais que afetam a sociedade contemporânea.

$\mathrm{Na}$ categoria naturalismo, por sua vez, os discursos elaborados sobre a temática ambiental possuem como núcleo os argumentos a ideia de que o ser humano representa o fator mais importante de alteração do equilíbrio ambiental. Tais discursos

[...] veem o homem apenas como fator de alteração do equilíbrio de um meio; daquelas análises que não falam de sociedade, mas apenas da ação antrópica, uma variável a mais num conjunto de fatores basicamente naturais. A relação ser humano-natureza é concebida sem a mediação das relações sociais. (MORAES, 2002, p. 55)

Se no caso do naturalismo a dimensão política está ausente ou, em outras palavras, não é central na elaboração dos argumentos, na categoria denominada romantismo são destacados os discursos em que há uma excessiva politização das análises, na maioria das vezes com fundamentações frágeis ou inadequadas. Segundo Moraes: 


\begin{abstract}
Temos muito uma espécie de bom senso bem-intencionado, ingênuo, ao tomar a política como reino da pura vontade - como se a política não tivesse sua lógica e suas determinações [...] Do ponto de vista da questão ambiental, o romantismo se manifesta, por exemplo, no preservacionismo radical que, no limite, pode veicular perspectivas anti-humanísticas ao colocar a natureza como um valor maior que o homem. (MORAES, 2002, p. 55)
\end{abstract}

Além das categorias destacadas por Moraes (2002), o conteúdo presente nos discursos sobre a temática ambiental também pode ser classificado em uma categoria denominada crítica. Nessa perspectiva, o núcleo da argumentação gira em torno da ideia de que a temática ambiental está diretamente relacionada ao modelo excludente de sociedade que vigora atualmente. Nesses discursos também é frequente a indicação de que a origem dos problemas ambientais está articulada ao modo como o ser humano pensa e torna a natureza presente (BORHEIM, 1995). Essa categoria é denominada crítica por apontar que a resolução dos problemas ambientais passa necessariamente por uma transformação do modelo de sociedade consumista e excludente que vivenciamos. Parte dessas reflexões possui, por exemplo, a indicação do esgotamento do modelo de organização social identificado pelo termo american way of life.

Nessa perspectiva, autores como Leff (2002) elaboram importantes críticas às racionalidades econômica e tecnológica vigentes. Para o autor, a crise ambiental problematiza o conhecimento do mundo e coloca todos diante do não pensado, da incerteza e da complexidade. Desse modo, “[...] a crise ambiental constitui um chamado à reconstrução social do mundo: apreender a complexidade ambiental" (LEFF, 2002, p. 218).

Esses diferentes posicionamentos sobre a temática ambiental apontam para as concepções que os sujeitos e/ou grupos sociais organizados possuem sobre a temática ambiental e, também, têm relevante significado para a elaboração de práticas sociais, incluindo aquelas realizadas em espaços educacionais formais e/ ou não formais. Nessa mesma linha de entendimento, alguns trabalhos (CARVALHO, 1989; LORENZETTI, DELIZOICOV, 2009; SILVA, 2007) enfatizam que diferentes discursos que versam sobre a temática ambiental, sobretudo aqueles construídos por especialistas no campo da Educação, influenciam direta e indiretamente a elaboração e a execução de trabalhos educativos em ambientes formais e não formais de ensino.

Importante ressaltar que, independente dos posicionamentos político-ideológicos ou das compreensões teóricas sobre a temática ambiental, a educação é sempre vista como um processo fundamental nas buscas de soluções para os problemas relacionados com os impactos ambientais e suas consequências para as diferentes formas de vida, incluindo a humana (CARVALHO, 2006).

Porém, assim como há diferentes concepções sobre a temática ambiental, também existe um extenso espectro de compreensões sobre o papel do processo educativo para o enfrentamento da crise ambiental. Algumas dessas compreensões podem ser admitidas como sendo ingênuas, sobretudo ao considerar que o processo educativo, de forma exclusiva, possui a capacidade de transformar e reverter 
os principais problemas existentes em nossa realidade. Nesse sentido, Carvalho (2011) destaca que

[...] o uso cada vez mais corrente e generalizado da denominação "Educação Ambiental" pode contribuir para uma apreensão ingênua da ideia contida nela, como se fosse uma reunião de palavras com poder de abrir as portas para um amplo e extensivo campo de consenso. Com frequência se dissemina a ideia simplista de que, cada vez que essas palavras quase mágicas são mencionadas ou inseridas em um projeto ou programa de ação, imediatamente está garantido um campo de alianças e de compreensões comuns a unir todos os educadores de boa vontade desejosos de ensinar as pessoas a ser mais gentis e cuidadosas com a natureza. (CARVALHO, 2011, p. 153)

Entende-se que visões ingênuas sobre as possibilidades de o processo educativo enfrentar a crise ambiental devem ser superadas. Pois, de modo geral, admite-se que discursos educativos voltados, única e exclusivamente, para modificações comportamentais não contribuem, de forma mais significativa, para que estudantes compreendam as complexidades inerentes à temática ambiental.

Em outra perspectiva encontram-se os discursos elaborados por especialistas do âmbito educativo que apontam para o desenvolvimento de propostas educativas que possibilitem problematizar as dimensões políticas, sociais e econômicas que se articulam com a temática ambiental. Enfatiza-se que a formação dos sujeitos deve ser pautada pela perspectiva do pensar e do agir criticamente na sociedade, baseado nas vias de emancipação e de transformação social.

Partindo dessas ponderações, entende-se relevante para a área de Ensino de Ciências e, em particular, para a de Ensino de Física a elaboração de pesquisas cujo intuito seja investigar as diferentes compreensões dos investigadores/ professores dessa área sobre a temática ambiental e/ou a temática ambiental e o processo educativo. Nesse caso, compreende-se que a investigação da produção teórica da área sobre o assunto se apresenta como uma das mais promissoras de serem investigadas, já que a pesquisa em tais documentos pode vir a sistematizar e a valorizar o conhecimento já produzido pelo campo do Ensino de Física sobre a temática ambiental e/ou a temática ambiental e o processo educativo.

A partir desse contexto elaborou-se a seguinte questão: que compreensões sobre a temática ambiental e as articulações entre esta e o processo educativo podem ser inferidas a partir da análise das informações contidas nos artigos, nos quais essa temática é central, apresentados nos Encontros de Pesquisa em Ensino de Física entre os anos de 2000 e 2012?

O recorte organizacional se justifica por dois fatores. O primeiro é que, tradicionalmente, muitos pesquisadores da área de Ensino de Ciências divulgam sua produção, por vezes exclusivamente, nos eventos da área (MARTINS; FERNANDES; ABREU, 2010). O segundo está relacionado ao fato de que o Encontro de Pesquisa em Ensino de Física (EPEF) é um dos principais encontros tópicos da área de pesquisa em Ensino de Física. Este é promovido, bianualmente, pela Sociedade Brasileira de Física (SBF), desde 1986, e constitui-se em um espaço 
privilegiado para a troca de ideias e experiências entre os pesquisadores do país. Diante dessas considerações, entende-se que os trabalhos apresentados no EPEF representam de forma significativa o conjunto das investigações desenvolvidas pela área de pesquisa em Ensino de Física no país, incluindo relatos de estratégias e práticas educacionais que nem sempre estão presentes nos artigos publicados nos periódicos.

O recorte temporal (2000-2012) se justifica pelo fato de que nesse período houve um maior interesse da área pelos trabalhos que apresentam, de forma mais concreta, algumas possibilidades de abordar aspectos da temática ambiental em processos educativos (MARTINS; FERNANDES; ABREU, 2010).

\section{PROCEDIMENTOS PARA COLETA E ANÁLISE DOS DADOS}

Para o desenvolvimento da presente pesquisa foi realizado, inicialmente, um levantamento bibliográfico dos trabalhos publicados nas atas digitalizadas dos EPEF nas edições realizadas em 2000, 2002, 2004, 2006, 2008, 2010 e 2012. Não foram considerados os trabalhos do XIII EPEF, realizado em Foz do Iguaçu em 2011, pois essa edição foi organizada de forma excepcional e possuiu características distintas das outras, a saber: 1 - foi realizado em sessões comuns a todas as áreas de Física existentes na SBF em um grande congresso denominado "Encontro de Física 2011"; 2- foram aceitos única e exclusivamente resumos estendidos de até três páginas.

Em uma primeira etapa, por meio de ferramenta computacional de localização de palavras em textos, buscou-se as expressões "meio ambiente", "temática ambiental", "problemática ambiental", "educação ambiental”, "degradação ambiental" e "crise ambiental" nos textos completos disponibilizados pelas atas das referidas edições do EPEF. Dessa forma foram selecionados 122 trabalhos.

$\mathrm{Na}$ segunda etapa realizou-se a leitura de 111 resumos e 11 trabalhos completos que não tiveram seus resumos divulgados nas atas do VII EPEF. A partir desta, foram excluídos 91 trabalhos das edições compreendidas entre 2002 e 2012 e oito da edição de 2000 (VII EPEF), tendo em vista que a temática ambiental e/ou a temática ambiental e o processo educativo apenas tangenciavam as análises e reflexões apresentadas.

Em uma terceira etapa foi realizada a leitura na íntegra dos 20 trabalhos completos restantes, relativos às edições do EPEF realizadas no período de 2002 até 2012. A partir dessa leitura foram descartados mais quatro artigos ${ }^{1}$. Nesse sentido, o corpus documental dessa investigação é constituído de 19 trabalhos, sendo três da edição do EPEF de 2000 e 16 das edições seguintes. Nestes os autores apresentam, explicitamente, considerações sobre a temática ambiental e/ou esta e o processo educativo. Na tabela 1 resume-se o processo de seleção dos artigos em cada etapa do processo de construção do corpus documental desta investigação. 
TABELA 1 - Número de artigos selecionados nas diferentes etapas do processo de constituição do corpus documental

\begin{tabular}{|c|c|l|l|l|}
\hline Ano & $\begin{array}{l}\text { No de artigos } \\
\text { presente nas } \\
\text { atas do evento }\end{array}$ & $\begin{array}{l}\text { No de artigos } \\
\text { selecionados na } \\
\text { primeira etapa }\end{array}$ & $\begin{array}{l}\text { No de artigos } \\
\text { selecionados } \\
\text { na segunda } \\
\text { etapa }\end{array}$ & $\begin{array}{l}\text { No de artigos } \\
\text { selecionados } \\
\text { na terceira } \\
\text { etapa }\end{array}$ \\
\hline 2000 & 161 & 16 & 03 & 03 \\
\hline 2002 & 83 & 11 & 03 & 02 \\
\hline 2004 & 147 & 16 & 02 & 02 \\
\hline 2006 & 107 & 08 & 02 & 02 \\
\hline 2008 & 162 & 26 & 05 & 05 \\
\hline 2010 & 149 & 23 & 05 & 03 \\
\hline 2012 & 199 & 22 & 03 & 02 \\
\hline Total & 1008 & 122 & 23 & 19 \\
\hline
\end{tabular}

O quadro 1 apresenta a identificação dos trabalhos que formam o corpus documental da presente investigação.

QUADRO 1 - Identificação dos trabalhos que formam o corpus documental desta investigação

\begin{tabular}{|c|c|c|}
\hline Título do trabalho & Autor/ Ano & Encontro \\
\hline $\begin{array}{c}\text { Um breve ensaio sobre eventuais } \\
\begin{array}{c}\text { contribuições da Física para o estudo de } \\
\text { questões educacionais, ambientais e de } \\
\text { desenvolvimento }\end{array}\end{array}$ & Bastos Filho (2000) & VII EPEF \\
\hline O meio ambiente e o ensino de Física & Santos e Kawamura (2000) & VII EPEF \\
\hline $\begin{array}{c}\text { Análise de um texto paradidático sobre } \\
\text { energia e meio ambiente }\end{array}$ & Benjamin e Teixeira (2000) & VII EPEF \\
\hline $\begin{array}{c}\text { A análise do efeito estufa em textos } \\
\text { paradidáticos e periódicos jornalísticos }\end{array}$ & Xavier e Kerr (2002) & VIII EPEF \\
\hline $\begin{array}{c}\text { A compreensão dos alunos do ensino } \\
\text { médio quanto ao tema produção de energia } \\
\text { elétrica em larga escala }\end{array}$ & Silva e Carvalho (2002) & VIII EPEF \\
\hline $\begin{array}{c}\text { Desenvolvimento sustentável e ensino de } \\
\text { Física }\end{array}$ & Sousa e Kawamura (2004) & IX EPEF \\
\hline $\begin{array}{c}\text { A temática ambiental e o ensino de } \\
\text { Física na escola média: avaliação do } \\
\text { posicionamento dos alunos em relação a } \\
\text { aspectos controversos }\end{array}$ & Silva e Carvalho (2004) & IX EPEF \\
\hline
\end{tabular}




\begin{tabular}{|c|c|c|}
\hline $\begin{array}{l}\text { Uma abordagem temática para a questão } \\
\text { da água }\end{array}$ & $\begin{array}{l}\text { Watanabe e Kawamura } \\
\text { (2006) }\end{array}$ & $X$ EPEF \\
\hline $\begin{array}{l}\text { O ensino de Física e a temática ambiental: } \\
\text { a produção de energia elétrica em larga } \\
\text { escala como um tema controverso }\end{array}$ & Silva e Carvalho (2006) & $X$ EPEF \\
\hline $\begin{array}{l}\text { Física e meio ambiente no ensino } \\
\text { fundamental }\end{array}$ & $\begin{array}{l}\text { Assis Jr., Assis e Carvalho } \\
\text { (2008) }\end{array}$ & XI EPEF \\
\hline $\begin{array}{c}\text { Formação de professores de Física e } \\
\text { implicações da relação ciência, tecnologia, } \\
\text { sociedade e ambiente: possibilidades, } \\
\text { desafios e limitações }\end{array}$ & $\begin{array}{l}\text { Alves, Mion e Carvalho } \\
\text { (2008) }\end{array}$ & XI EPEF \\
\hline $\begin{array}{l}\text { Construção de estratégias pedagógicas } \\
\text { em ciência-tecnologia-sociedade (CTS) } \\
\text { para a formação de professores: a energia } \\
\text { elétrica na sala de aula }\end{array}$ & $\begin{array}{l}\text { Bernardo, Vianna e } \\
\text { Fontoura (2008) }\end{array}$ & XI EPEF \\
\hline $\begin{array}{l}\text { O ciclo dialético questionamento- } \\
\text { argumentação-comunicação em uma } \\
\text { proposta de estudo das questões } \\
\text { energéticas na sala de aula de Física }\end{array}$ & Prestes e Silva (2008) & XI EPEF \\
\hline $\begin{array}{c}\text { Professores de Física em formação inicial: } \\
\text { o ensino de Física, a temática ambiental e } \\
\text { os temas controversos }\end{array}$ & Silva e Carvalho (2008) & XI EPEF \\
\hline $\begin{array}{l}\text { Abordagem do aquecimento global em } \\
\text { livros didáticos de física do ensino médio }\end{array}$ & $\begin{array}{l}\text { Santos e Souza Barros } \\
\text { (2010) }\end{array}$ & XII EPEF \\
\hline $\begin{array}{l}\text { Uma abordagem termodinâmica para } \\
\text { discutir a física do meio ambiente }\end{array}$ & $\begin{array}{l}\text { Watanabe-Caramello e } \\
\text { Kawamura (2010) }\end{array}$ & XII EPEF \\
\hline $\begin{array}{c}\text { Futuros professores de física e a } \\
\text { compreensão sobre o tema mudanças } \\
\text { climáticas }\end{array}$ & $\begin{array}{l}\text { Reis, Silva, L. e Silva, A. } \\
\text { (2010) }\end{array}$ & XII EPEF \\
\hline $\begin{array}{l}\text { O uso da abordagem CTSA no ensino } \\
\text { de energia tendo o desenvolvimento } \\
\text { sustentável como eixo temático }\end{array}$ & Lima Neto e Barreto (2012) & XIV EPEF \\
\hline $\begin{array}{l}\text { Aproximações e contrapontos: } \\
\text { complexificação do conhecimento cotidiano } \\
\text { e abordagem temática }\end{array}$ & $\begin{array}{l}\text { Watanabe-Caramello e } \\
\text { Kawamura (2012) }\end{array}$ & XIV EPEF \\
\hline
\end{tabular}

Fonte: Elaborada pelos autores.

Após a delimitação do corpus documental elaborou-se uma ficha de leitura para cada trabalho e iniciou-se o processo de análise de dados. Esta foi realizada a partir dos procedimentos da Análise de Conteúdo. Segundo Bardin (2009), esta consiste em:

Um conjunto de técnicas de análise das comunicações visando obter por procedimentos sistemáticos e objetivos de descrição do conteúdo das mensagens indicadores (quantitativos ou não) que permitam a inferência de conhecimentos relativos às condições de produção/recepção (variáveis inferidas) destas mensagens. (BARDIN, 2009, p. 44) 
Oliveira et al. (2003) pontuam que as técnicas da análise de conteúdo possibilitam a identificação dos principais conceitos e/ou temas presentes nos textos. Ainda de acordo com os autores, o principal objetivo dessa técnica de análise dos dados é fornecer "[...] indicadores úteis aos objetivos da pesquisa" (OLIVEIRA et al., 2003, p. 6). Dessa maneira, o pesquisador possui a liberdade de interpretar seus resultados relacionando-os ao contexto de produção do documento, bem como aos objetivos do indivíduo ou organização/instituição que o elaborou.

A Análise de Conteúdo, segundo Bardin (2009), pode ser realizada a partir de duas práticas: a linguística e as técnicas documentais. No caso da presente pesquisa, em que são analisados os trabalhos apresentados em congressos, entende-se que ela esteja atrelada às técnicas documentais.

A análise se organizou a partir de três "polos cronológicos": pré-análise; exploração do material e o tratamento dos resultados; e a inferência e a interpretação.

Dentre as diferentes técnicas de análise de conteúdo, utilizou-se aquela reconhecida por análise temática ou categorial. Realizar a análise temática consiste em identificar os núcleos de sentido que compõem a mensagem (conteúdo). A presença ou frequência de aparição dos núcleos de sentido no texto podem possuir algum significado para o objetivo do trabalho realizado. Em relação à análise por categorias, Bardin (2009) afirma que:

No conjunto das técnicas da análise de conteúdo, é de se citar em primeiro lugar a análise por categorias; cronologicamente é a mais antiga; na prática é a mais utilizada. Funciona por operações de desmembramento do texto em unidades, em categorias segundo reagrupamentos analógicos. Entre as diferentes possibilidades de categorização, a investigação dos temas, ou análise temática, é rápida e eficaz na condição de se aplicar a discursos diretos. (BARDIN, 2009, p. 199)

Nesse caso os temas também são reconhecidos por unidades de registro ou núcleos de sentido da mensagem. O tema é definido por Bardin (2009, p. 131) como "[...] uma afirmação acerca de um assunto [...], uma frase ou uma frase composta, habitualmente um resumo ou uma frase condensada, por influência da qual pode ser afetado um vasto conjunto de formações singulares”. A identificação dos temas ocorre na fase da codificação da mensagem.

Em seguida, na fase da categorização, ocorre a divisão dos temas em classes segundo as suas características comuns. Oliveira et al. definem que:

A categorização gera classes que reúnem um grupo de elementos da unidade de registro. As classes são compiladas a partir da correspondência entre a significação, a lógica do senso comum e a orientação teórica do pesquisador. Portanto, os critérios para a categorização podem ser semânticos; sintáticos; léxico ou expressivos. Ainda Bardin (1979) indica a possibilidade de uma categorização com categorias a priori, sugeridas pelo referencial teórico e com categorias a posteriori, elaboradas após a análise do material. (OLIVEIRA et al., 2003, p. 9) 
Os mesmos autores ainda afirmam que o sistema de categorização ocorrerá mediante um reagrupamento progressivo de categorias, variando desde uma amplitude de generalidade mais forte até uma generalidade mais fraca (o que caracteriza as subcategorias). Também é importante afirmar que, para aqueles que optam pela construção de categorias a priori, deve-se levar em consideração a orientação teórica e os objetivos da pesquisa para construção das mesmas.

Laville e Dionne (1999), discorrendo sobre a análise de conteúdo, apresentam, além de categorias definidas a priori (modelo fechado) e a posteriori (modelo aberto), um terceiro modelo de categorização: o modelo misto. Esse modelo serve-se dos modelos aberto e fechado, em que as categorias são definidas no início, mas o pesquisador se permite modificá-las em função do que a análise aportará, ou seja, a construção das categorias inicia-se com a definição de categorias a priori fundadas com auxílio do aporte teórico utilizado pelo pesquisador, no entanto, estas não possuem um caráter imutável, já que, durante a leitura do material submetido à análise, as categorias preestabelecidas podem sofrer algumas modificações, sendo até mesmo excluídas e outras podem ser criadas.

Neste trabalho optou-se pela forma mista de categorização, sobretudo porque parte-se de categorias a priori - dadas por pesquisas que já realizaram trabalhos parecidos - mas, em vários momentos, foram necessárias modificações e novas organizações categóricas.

Nas seções subsequentes são apresentados os resultados da presente investigação.

\section{COMPREENSÕES DOS PESQUISADORES QUE ATUAM NA ÁREA DE ENSINO DE FÍSI- CA SOBRE A TEMÁTICA AMBIENTAL}

Nesta seção são apresentadas as análises que indicam as compreensões de pesquisadores que atuam na área de Ensino de Física sobre a temática ambiental. Todavia, inicialmente destacam-se duas considerações sobre o corpus documental desta investigação.

A primeira se refere à frequência com a qual alguns pesquisadores são identificados nos trabalhos analisados. A pesquisadora Kawamura é coautora em cinco artigos, e os pesquisadores Silva e Carvalho são autores de outros quatro trabalhos. Dessa forma, esses acadêmicos estão presentes em aproximadamente $47 \%$ dos trabalhos que formam o corpus documental desta investigação.

A segunda se refere ao fato de a área de pesquisa em Ensino de Física abordar de forma ainda tímida a temática ambiental nos trabalhos apresentados nos Encontros de Pesquisa em Ensino de Física no período compreendido entre 2000 e 2012. Esse dado pode ser enfatizado pelas informações expostas na tabela 2. 
TABELA 2 - Relação percentual, por evento, entre trabalhos que apresentam explicitamente considerações sobre a temática ambiental e/ou a temática ambiental e o processo educativo e o total de artigos presentes nas atas dos eventos

\begin{tabular}{|c|c|}
\hline Ano do evento & Indicação percentual (\%) \\
\hline 2000 & 1,9 \\
\hline 2002 & 2,4 \\
\hline 2004 & 1,4 \\
\hline 2006 & 1,9 \\
\hline 2008 & 3,1 \\
\hline 2010 & 2,0 \\
\hline 2012 & 1,0 \\
\hline
\end{tabular}

Santos, Carvalho e Levinson (2014) corroboram, de certo modo, com essa informação. Nesse artigo, os autores sistematizam resultados relacionados com a dimensão política da Educação Ambiental apresentada em artigos empíricos publicados em periódicos brasileiros da área de Ensino de Ciências classificados como A1, A2, B1 e B2 nas áreas de Ensino e de Educação no sistema Qualis/Capes. Dentre os resultados destaca-se o fato de que aproximadamente 1\% dos artigos publicados nas revistas disciplinares brasileiras da área de Ensino de Física - Caderno Brasileiro de Ensino de Física e Revista Brasileira de Ensino de Física - estabelecem relação entre a temática ambiental e o processo educativo. Esse resultado, segundo os autores, evidencia a pouca tradição desses periódicos na publicação de pesquisas que estabelecem relação com a Educação Ambiental.

O baixo número de trabalhos que abordam a temática ambiental apresentados no EPEF é mais relevante ao se admitir que as preocupações voltadas para a problemática ambiental cresceram de forma significativa nos últimos 20 anos. Além disso, muitos aspectos da temática ambiental são compreendidos de maneira mais abrangente a partir dos conhecimentos sistematizados pela Física.

Uma análise mais qualitativa dos trabalhos selecionados nesta investigação indica que os pesquisadores da área que se envolvem com a temática ambiental apresentam, em sua maioria, uma perspectiva crítica na abordagem desse tema. Nesse sentido, há claras menções sobre as complexidades, as controvérsias e as incertezas relacionadas aos problemas ambientais.

Em vários trabalhos há menções sobre as controvérsias e as complexidades inerentes à temática ambiental. Nos trabalhos de Watanabe-Caramello e Kawamura (2012), Watanabe-Caramello e Kawamura (2010), Reis, Silva, L. e Silva, A. (2010), Prestes e Silva (2008), Silva e Carvalho (2004, 2006), Xavier e Kerr (2002) e Bastos Filho (2000) são frequentes núcleos temáticos nos quais há indicações sobre a natureza complexa da temática ambiental. 
No texto de Watanabe-Caramello e Kawamura (2012), por exemplo, há a seguinte indicação sobre a complexidade dos fenômenos socioambientais:

[...] a discussão socioambiental coloca em evidência a nossa dificuldade em lidar com sistemas complexos o que, por sua vez, nos remete a um questionamento sobre os paradigmas tradicionais, implicando incorporar a complexidade para tratar as questões. (WATANABE-CARAMELLO; KAWAMURA, 2012, p. 2)

Nesse trabalho as autoras apontam para a necessidade de superar a visão determinista de ciência, como capaz de gerar previsões acuradas do comportamento de sistemas mais complexos como, por exemplo, os sistemas climáticos. Há o indicativo de que essa visão de ciência não está apta a lidar com temas socioambientais.

Nos outros sete trabalhos, a menção sobre a complexidade dos fenômenos ambientais é realizada de forma pontual. As indicações são relativas às incertezas inerentes aos modelos científicos que descrevem os fenômenos ambientais. $\mathrm{O}$ artigo de Bastos Filho (2000), por exemplo, indica que os sistemas ambientais são complexos e que os conhecimentos sistematizados pela Física, por si só, não são suficientes para dar conta dessa complexidade.

Nesse sentido, nota-se que detalhamentos e aprofundamentos sobre a complexidade dos problemas ambientais não constituem um elemento central de atenção nos trabalhos mencionados. Estes apresentam considerações que apenas tangenciam a complexidade dos fenômenos socioambientais. Em outras palavras, não há nos trabalhos analisados uma reflexão mais profunda sobre a compreensão das questões socioambientais na perspectiva do pensamento complexo. Nesse caso, é interessante indicar que considerações mais aprofundadas dessa natureza podem ser encontradas na tese de doutorado de Watanabe-Caramello (2012) e no artigo de Watanabe-Caramello e Kawamura (2014).

Nos trabalhos de Reis, Silva, L. e Silva, A. (2010) e Silva e Carvalho (2004, 2006) há um destaque maior para as controvérsias inerentes aos temas socioambientais, sobretudo aqueles decorrentes da modelagem dos fenômenos climáticos. São enfatizadas, também, controvérsias inerentes aos impactos sociais e ambientais produzidos a partir da construção de usinas geradoras de energia elétrica em larga escala - hidroelétricas, termoelétricas e termonucleares. O seguinte excerto exemplifica esse posicionamento: “O tema do aquecimento global é apenas um dos exemplos, dentre vários, que poderiam ser melhor compreendidos a partir de uma análise das controvérsias que lhe são inerentes" (SILVA; CARVALHO, 2006, p. 3).

A partir dos núcleos temáticos que apontam para a perspectiva das controvérsias e complexidades inerentes à temática ambiental elaborou-se, nas análises realizadas, o agrupamento "Complexidades e Controvérsias Inerentes à Temática Ambiental".

Outro aspecto que chama a atenção em alguns trabalhos está diretamente relacionado à perspectiva crítica explicitada com relação ao modelo econômico 
vigente. Os trabalhos de Silva e Carvalho (2004, 2006), Sousa e Kawamura (2004), Xavier e Kerr (2002) e Bastos Filho (2000) apresentam críticas ao sistema econômico vigente ao abordar aspectos da temática ambiental.

Especificamente em três trabalhos (BASTOS FILHO, 2000; SILVA; CARVALHO, 2004, 2006) há uma crítica explícita ao american way of life. No trabalho de Silva e Carvalho (2004) é mencionado que:

Evidencia-se, através destes debates, a necessidade de se repensar o modelo de desenvolvimento vigente que orienta as organizações humanas, que tem como um de seus pressupostos básicos o consumo intensivo perdulário de mercadorias e de energia, traduzido de forma mais explícita no chamado american way of life. (SILVA; CARVALHO, 2004, p. 4)

Nesses trabalhos, os autores criticam a ideia de desenvolvimento presente no ideário moderno, sobretudo o fato de que esta está amparada na crença de um crescimento ilimitado e na negação do limite da natureza. Em nome de um progresso ilimitado observa-se o surgimento de complexos e profundos problemas sociais e ambientais. Essa situação é um forte indicativo do colapso do estilo de desenvolvimento moderno, não só dos fatores econômico e ambiental, mas também daquele referente à justiça social. É nessa perspectiva que se situa a compreensão da incompatibilidade entre o estilo econômico representado pelo american way of life e o debate em torno da sustentabilidade, tratada nas suas dimensões ambiental, social, política, econômica e cultural.

Apontamentos dessa natureza possibilitaram a construção do agrupamento "Críticas ao Modelo Vigente de Sociedade".

Outro destaque das análises realizadas se volta para os trabalhos (ALVES, MION; CARVALHO, 2008; WATANABE; KAWAMURA, 2006) que explicitam a articulação entre problemáticas ambientais locais e globais, aspecto que motivou a elaboração do agrupamento "Local-Global-Local". Alves, Mion e Carvalho (2008), por exemplo, indicam que:

[...] danos ambientais decorrentes da ação humana, como a contaminação envolvendo parques industriais, a exemplo do que ocorrera em Cubatão (litoral paulista), as chuvas ácidas na Mata Atlântica (principalmente em território paulista), a poluição do Rio Tietê (no Estado de São Paulo), a seca no Nordeste brasileiro e os processos de desertificação em diferentes Estados desta nação eram tratados por educadores, políticos, sociólogos, filósofos e profissionais da comunicação como fatores oriundos de causas e consequências isoladas, tendo como forte argumento o fato de que esses eram motivados localmente, em razão da negligência de determinadas pessoas, grupos econômicos ou políticos. O que se constata hoje é que esse tipo de causa pode ser local, mas as motivações e os efeitos são globais. (ALVES; MION; CARVALHO, 2008, p. 5)

Percebe-se que os agrupamentos "Complexidades e Controvérsias Inerentes à Temática Ambiental", "Críticas ao Modelo Vigente de Sociedade" e "Local-Global-Local” possuem vários elementos que convergem para a categoria dada 
a priori denominada "crítica". Nos trabalhos presentes nesses agrupamentos é frequente a indicação de que a origem dos problemas ambientais está articulada ao modo como pensamos e nos relacionamos com o mundo como, por exemplo, considerações sobre incertezas, controvérsias e complexidades. Além disso, há uma série de críticas ao modelo econômico vigente.

A análise realizada ainda possibilita destacar que o tema sustentabilidade é frequente em cinco trabalhos (LIMA NETO; BARRETO, 2012; ASSIS JUNIOR et al., 2008; WATANABE; KAWAMURA, 2006; SOUSA; KAWAMURA, 2004; BASTOS FILHO, 2000). O excerto a seguir exemplifica essa indicação:

A ênfase que gostaríamos de dar está circunscrita à questão ética. Deste modo, desenvolvimento e envolvimento devem estar ligados por um elo ético. Tudo isso nos faz lembrar o conceito de desenvolvimento sustentável do Relatório Brundtland. (BASTOS FILHO, 2000, p. 9)

De modo especial, observa-se que em um desses trabalhos a discussão sobre a sustentabilidade está explicitamente ligada ao tema Produção e Consumo de Energia Elétrica (ASSIS JUNIOR; ASSIS; CARVALHO, 2008).

Todavia, mesmo considerando a existência de núcleos de conteúdo que convergem para uma perspectiva mais crítica voltada à relação sociedade e natureza, verifica-se que, com exceção do texto de Sousa e Kawamura (2004), não há nesses trabalhos considerações mais críticas direcionadas à proposta do "desenvolvimento sustentável”. Segundo Lima (2002, p. 2) essa é “[...] uma proposta em torno da qual gravitam múltiplas e diversas forças sociais, interesses e leituras que disputam entre si o reconhecimento e legitimação social como 'a interpretação verdadeira' sobre o tema".

Nesse sentido, não está apresentada na maioria dos trabalhos que abordam a sustentabilidade uma análise mais aprofundada sobre a dimensão política dos diferentes discursos sobre esse tema. Não se explicita um posicionamento mais crítico com relação à conciliação entre a perspectiva econômica vigente com a preservação da natureza, sendo esta uma ideia muitas vezes implícita em algumas considerações sobre o desenvolvimento sustentável.

Importante indicar que todos os trabalhos do corpus documental desta investigação apontam para diferentes articulações entre a temática ambiental e outros aspectos da realidade, tais como os aspectos sociais, econômicos, tecnológicos, científicos e políticos.

Como já exposto, além da visão sobre a relação sociedade-natureza, também procurou-se analisar nesses textos as considerações dos autores sobre o processo educativo e a temática ambiental, assunto da próxima seção.

\section{CONSIDERACִ̃̃ES DOS PESQUISADORES QUE ATUAM NA ÁREA DE ENSINO DE FÍSICA SOBRE A TEMÁTICA AMBIENTAL E O PROCESSO EDUCATIVO}

Nesta etapa do trabalho apresentam-se as articulações elaboradas pelos pesquisadores atuantes na área de Ensino de Física entre a temática am- 
biental e o processo educativo.

Inicialmente destaca-se o fato de que sete dos 19 trabalhos analisados fazem menção à Educação Ambiental. Os trabalhos de Assis Junior, Assis e Carvalho (2008), Watanabe e Kawamura (2006), Sousa e Kawamura (2004), Silva e Carvalho (2004), Bastos Filho (2000), Santos e Kawamura (2000) e Benjamin e Teixeira (2000) articulam, de diferentes formas, o campo do Ensino de Física com o da Educação Ambiental.

Os trabalhos de Bastos Filho (2000), Benjamin e Teixeira (2000) e Santos e Kawamura (2000) fazem breves menções aos processos educativos dessa natureza, porém, os outros trabalhos associam explicitamente o Ensino de Física e os diferentes aspectos da Educação Ambiental. O excerto a seguir exemplifica essa perspectiva:

Contudo, os resultados mostraram que o desenvolvimento de atividades que envolvam educação ambiental em aulas de Física, mediante a interação entre professor, alunos e textos, pode propiciar aos alunos a compreensão relativa aos conceitos de transformação, conservação, formas e fontes de energia. Pode ainda promover aos alunos a articulação entre esses conceitos e os aspectos ambientais, o que pode viabilizar que eles atuem em seu cotidiano de forma crítica e consciente, agindo enquanto elementos propagadores da educação ambiental, a fim de contribuírem para a preservação do meio ambiente. (ASSIS JUNIOR; ASSIS; CARVALHO, 2008, p. 11)

O trabalho de Sousa e Kawamura (2004) apresenta explicitamente a perspectiva da Educação Ambiental crítica. O excerto a seguir exemplifica esse posicionamento:

[...] na perspectiva de uma educação ambiental crítica, trata-se de buscar rediscutir a própria relação da sociedade com a natureza, o que inclui as relações sociais para além das motivações individuais, as relações de poder e os interesses que movem as intenções. No caso do ensino de Física, vamos procurar mostrar que deveriam incluir também uma conscientização da relação de dominação do homem sobre a natureza que, implicitamente, permeia as chamadas ciências exatas. (SOUSA; KAWAMURA, 2004, p. 2)

Chama a atenção, no agrupamento de trabalhos que fazem referência à Educação Ambiental, a menção, nos artigos de Assis Junior, Assis e Carvalho (2008), Souza e Kawamura (2004) e Benjamin e Teixeira (2000), ao termo conscientização. Todavia, nesses artigos, esse termo não é problematizado e, frequentemente, pode ser identificado com a palavra "conhecer". O excerto a seguir explicita esse apontamento:

Em resposta a estas questões, acreditamos que a nossa melhor atuação seria posicionando-nos enquanto educadores a fim de contribuir significativamente para a formação do aluno, enquanto cidadão consciente dos problemas sociais, políticos, econômicos, científicos e tecnológicos do seu cotidiano. Pensamos então na possibilidade de utilizarmos o livro como recurso didático, com o propósito de levar o aluno a uma compreensão mais abrangente sobre energia, de modo a perceber a influência das transformações e conservação da energia sobre o equilíbrio ecológico. (BENJAMIN; TEIXEIRA, 2000, p. 1) 
Se em sete trabalhos há menção explicita à Educação Ambiental, em nove verifica-se a articulação entre a temática ambiental e o enfoque Ciência, Tecnologia e Sociedade (CTS) ou ao enfoque Ciência, Tecnologia, Sociedade e Ambiente (CTSA). Os trabalhos nessa perspectiva são os de Lima Neto e Barreto (2012), Santos e Barros (2010), Reis, Silva, L. e Silva, A. (2010), Prestes e Silva (2008), Bernardo, Vianna e Fontoura (2008), Alves, Mion e Carvalho (2008), Silva e Carvalho (2008), Watanabe e Kawamura (2006) e Sousa e Kawamura (2004). Em todos esses trabalhos há indicativos de que o processo educativo deve objetivar a formação de cidadãos críticos que participem ativamente de processos de tomada de decisão envolvendo aspectos da temática ambiental. O excerto que se segue exemplifica essa perspectiva:

Segundo Doménech et al. (2007), o tema energia vem sendo abordado de forma muito centrada em aspectos conceituais. Entretanto, os autores consideram que as implicações pessoais, sociais e ambientais, associadas ao tema, podem despertar o interesse dos estudantes em aprendê-lo, e chamam a atenção para a relevância dessas implicações quando se deseja formar cidadãos bem-informados e capazes de tomar decisões frente à atual situação de emergência planetária (GIL-PÉREZ; VILCHES, 2006). Assim, muitos autores recomendam uma abordagem baseada no enfoque ciência-tecnologia-sociedade-ambiente (CTSA) - visto por Aikenhead (2003) como um desdobramento do CTS, com ênfase no aspecto ambiental - para tratamento do tema, a fim de que o estudo ocorra de forma mais significativa para os estudantes. (BERNARDO; VIANNA; FONTOURA, 2008, p. 3)

Destaca-se que os trabalhos de Lima Neto e Barreto (2012), Bernardo, Vianna e Fontoura (2008), Prestes e Silva (2008) e Alves, Mion e Carvalho (2008) apontam para o termo CTSA, sendo que os outros trabalhos se voltam para a perspectiva CTS.

Interessante indicar que a abordagem de aspectos da temática ambiental em atividades de Ensino de Física a partir do enfoque CTSA tem sido tema de investigações mais recentes que colocam ênfase nas questões socioambientais. De modo especial, destaca-se o trabalho de MacLeod (2012), que examinou crenças, percepções, desafios e tensões que influenciam futuros professores de Física canadenses quando decidem adotar o enfoque CTSA no planejamento e na execução de práticas educativas.

A análise dos dados também aponta que é relevante o crescimento do número de trabalhos que abordam aspectos da temática ambiental a partir da articulação com o enfoque CTS/CTSA após o XI EPEF realizado em 2008. Esse dado é condizente com os resultados apontados pelas autoras Strieder e Kawamura (2009), em trabalho que identifica possíveis tendências CTS presentes no campo do Ensino de Ciências. Para as autoras:

[...] nos últimos anos é crescente o interesse e as preocupações com abordagens CTS, que vêm se expressando em relatos de trabalhos, comunicações em eventos da área, artigos em revistas ou teses e dissertações. (STRIEDER; KAWAMURA, 2009, p. 1) 
Todavia, conforme alertam as autoras, é necessário ter em consideração a polissemia associada aos termos CTS e CTSA. Nessa perspectiva, por exemplo, há diferentes encaminhamentos para o desenvolvimento de trabalhos que abordam aspectos da temática ambiental a partir do enfoque CTS e CTSA.

Nesse sentido, destaca-se o fato de que em nenhum dos trabalhos analisados existe uma problematização com relação aos valores estabelecidos pela cultura da sociedade capitalista. Segundo Santos, Carvalho e Levinson (2014), a promoção desses valores deveria ser um dos objetivos do Ensino de Ciências que incorporam a discussão da temática ambiental. Ainda segundo os autores, a cultura capitalista possui uma lógica centrada no individualismo. Nela prevalecem interesses privados em detrimento de interesses coletivos, sobretudo por meio da prática de atividade de competição entre indivíduos e/ou grupos.

Outro dado interessante desta investigação está no fato de o termo "conscientização" ser mencionado explicitamente em três trabalhos (BERNARDO; VIANNA; FONTOURA, 2008; ALVES; MION; CARVALHO, 2008; SANTOS; BARROS, 2010) identificados - nesta oportunidade - com o enfoque CTS/CTSA. O excerto que se segue exemplifica esse apontamento:

As temáticas ambientais se alinham, no contexto da Pesquisa em Educação em Ciências (PEC), com a proposta de ensino CTS (Ciência, Tecnologia e Sociedade). Trata-se da conscientização dos estudantes para analisarem e tratarem criticamente os vários desafios presentes numa sociedade moderna, pretendendo desmistificar os aspectos subjacentes às relações entre ciência, tecnologia e sociedade [...]. (SANTOS; BARROS, 2010, p. 6)

Verifica-se que nesses trabalhos o termo conscientização também não foi problematizado. Nesse sentido, não fica claro se o termo está ligado, por exemplo, ao significado que possui nos trabalhos do educador Paulo Freire.

Chama a atenção a menção, no trabalho de Sousa e Kawamura (2004), sobre a possibilidade de o professor de Física poder abordar aspectos da temática ambiental em aulas de Física na perspectiva do enfoque CTS ou no da Educação Ambiental.

\begin{abstract}
Assim, o objetivo desse trabalho é investigar o conceito de desenvolvimento sustentável, sua gênese, definição e seus indicadores, buscando identificar os elementos ambientais com potencial para orientar ou nuclear propostas voltadas para o ensino de física. Pretende-se com isso que, por exemplo, ao tratar do tema energia, na perspectiva da educação ambiental ou do movimento CTS, possamos de fato introduzir elementos formativos. (SOUSA; KAWAMURA, 2004, p. 2)
\end{abstract}

O trabalho de Sousa e Kawamura (2004) é o primeiro a explicitar, entre os trabalhos analisados, o enfoque CTS como uma possibilidade concreta de o professor de Física articular a temática ambiental e o processo educativo.

Foram identificados oito trabalhos nos quais há a indicação de que a te- 
mática ambiental pode ser abordada em aulas de Física a partir da perspectiva da "abordagem temática". Nesse sentido, temos os trabalhos de Lima Neto e Barreto (2012), Watanabe-Caramello e Kawamura (2012), Reis, Silva, L. e Silva, A. (2010), Silva e Carvalho (2002, 2006, 2008), Watanabe e Kawamura (2006), Sousa e Kawamura (2004).

Os trabalhos de Reis, Silva, L. e Silva, A. (2010) e Silva e Carvalho (2002, 2006, 2008), fazem referência específica à perspectiva de tratar temas controversos em aulas de Física. O excerto abaixo exemplifica esse posicionamento:

O tema do aquecimento global é apenas um dos exemplos, dentre vários, que poderiam ser melhor compreendidos a partir da análise das controvérsias que lhe são inerentes. A exploração destas controvérsias nos possibilita construir atividades pedagógicas que trazem à tona uma Ciência mais próxima da realidade, ou seja, uma Ciência que não é neutra, como não pode ser nenhuma atividade humana, que não possui verdades absolutas, pois está sujeita a erros e modificações inerentes aos seus princípios básicos, que não possuí lógicas e procedimentos metodológicos unitários, dado que as regras rígidas engessam e comprometem a criatividade do cientista. (SILVA; CARVALHO, 2006, p. 3)

No trabalho de Silva e Carvalho (2002) é destacada a compreensão de alunos da educação básica com relação a algumas controvérsias envolvendo a produção de energia elétrica em larga escala no Brasil. Nesse trabalho, a natureza da controvérsia envolve a discussão sobre riscos e benefícios decorrentes da utilização de diferentes processos tecnológicos para a produção de energia elétrica em larga escala. Todavia, a problematização relativa à natureza da controvérsia nesse trabalho não avança, sendo pautada por orientações educacionais do tipo "a favor" ou "contra" determinada forma de produzir energia elétrica. Segundo Ribeiro e Kawamura (2014), em análises dessa natureza,

[...] as controvérsias valem mais pelo levantamento do problema, mas correm o risco de, pela dificuldade em assumirem toda a complexidade dos aspectos envolvidos, permitirem, muitas vezes, simplificações exageradas. Também correm o risco de apontar soluções fáceis para situações complexas. (RIBEIRO; KAWAMURA, 2014, p. 165)

Portanto, segundo as autoras:

[...] do ponto de vista da educação ambiental, a utilização de tais controvérsias pode implicar uma falsa abordagem que, embora se justifique enquanto elemento de problematização, precisa ser administrada com muito cuidado. Diferentes situações, parâmetros, condições de contorno, especificidades podem gerar escolhas e avaliações das relações de risco muito diferentes. (RIBEIRO; KAWAMURA, 2014, p. 165)

De outro modo, no trabalho de Silva e Carvalho (2008), cuja ênfase se volta para os obstáculos que se apresentam aos futuros professores de Física no 
tratamento educativo de temas controversos em sala de aula, percebe-se que a discussão das controvérsias relacionadas com a temática ambiental ganha aprofundamento teórico, sobretudo ao apresentarem considerações que problematizam a natureza das controvérsias socioambientais. Importante destacar que esse trabalho apresenta resultados provenientes da tese de doutorado do primeiro autor ${ }^{2}$.

Já o trabalho de Reis, Silva, L. e Silva, A. (2010) aborda compreensões de futuros professores de Física sobre algumas controvérsias científicas relacionadas com o tema das mudanças climáticas atuais. Nesse caso, as controvérsias destacadas, em sua maioria, são provenientes de resultados de pesquisas científicas sobre o assunto. Todavia, os autores não avançam a discussão sobre a natureza das controvérsias não abordando, por exemplo, as limitações de uma determinada visão de ciência para lidar com sistemas complexos. Conforme aponta Ribeiro e Kawamura (2014), controvérsias dessa natureza derivam dos processos de medida das grandezas envolvidas. Ainda segundo as autoras:

As controvérsias constituem-se menos de relações de causalidade ou por construções conceituais e mais pela própria visão de ciência que, para lidar com sistemas complexos, precisa rever os modelos reducionistas, ou o paradigma da simplificação, e compreender o sentido dos resultados, das medidas e das previsões dos modelos utilizados. (RIBEIRO; KAWAMURA, 2014, p. 164)

Já em Lima Neto e Barreto (2012) e Sousa e Kawamura (2004), a abordagem temática é vinculada à discussão da sustentabilidade. Esta é vista, nesses trabalhos, como uma possibilidade de articular os conceitos da Física e a temática ambiental em aulas de Física. No trabalho de Sousa e Kawamura (2004), por exemplo, indica-se que o tema sustentabilidade enriquece a discussão sobre produtividade e eficiência energética. O excerto abaixo exemplifica essa consideração:

Podemos ilustrar esse potencial tomando como exemplo a questão da energia. Tradicionalmente, o tratamento dado ao tema energia no ensino de Física reduz-se à identificação das fontes e transformações de energia para uso social. Possibilidades de geração de energia por hidrelétricas, termoelétricas, nucleares, etc. são discutidas do ponto de vista dos aspectos tecnológicos, dos processos envolvidos. Em relação à questão ambiental, comparece em geral quando se discute a utilização da energia nuclear, talvez mais pelos riscos do que propriamente pelos danos ambientais. [...] Considerar o desenvolvimento sustentável como referência significaria, nesse caso, situar a discussão da energia segundo diferentes dimensões. (SOUSA; KAWAMURA, 2004, p. 10)

Destaca-se, também, na perspectiva do trabalho educativo com abordagem temática, o trabalho de Watanabe-Caramello e Kawamura (2012). Nesse artigo as pesquisadoras salientam a articulação entre a abordagem temática e as complexidades para tratar as questões socioambientais em sala de aula. Ressaltam ainda que o educador Paulo Freire é uma das principais referências para tratar da abordagem temática em aulas de Física. Além disso, as autoras indicam a neces- 
sidade da complexificação do conhecimento cotidiano pelo viés da abordagem temática.

É necessário enfatizar que, independente de o trabalho se colocar na proposta educativa do enfoque CTS/CTSA ou da Educação Ambiental, há, ainda, menções ao "papel da interação/diálogo" (XAVIER; KERR, 2002; SILVA; CARVALHO, 2002) e da "interdisciplinaridade" na abordagem educativa da temática ambiental (SOUSA; KAWAMURA, 2004; WATANABE; KAWAMURA, 2006; PRESTES; SILVA; CARVALHO, 2008). O trabalho de Sousa e Kawamura (2004), por exemplo, destaca que "[...] a questão do ambiente é necessariamente interdisciplinar, encontrar o espaço para a participação do ensino de física nesse contexto parece indispensável" (SOUSA; KAWAMURA, 2004, p. 1).

A partir dos inúmeros apontamentos destacados, é possível afirmar que a área de pesquisa em Ensino de Física, relatada aqui pelos trabalhos apresentados nos EPEF realizados entre 2000 e 2012, tende a assumir uma perspectiva educativa mais crítica com relação à abordagem da temática ambiental no processo educativo. Segundo Carvalho (2004), a perspectiva crítica da abordagem educativa da temática ambiental está relacionada com ideais democráticos e emancipatórios. Ainda segundo a autora, essa perspectiva rompe com outras de caráter mais "ingênuo" sobre a relação sociedade-natureza. A orientação da abordagem educativa crítica é dirigida por sensibilidades solidárias com o meio social e ambiental, objetivando a formação de indivíduos e grupos sociais capazes de identificar, problematizar e agir em relação às questões socioambientais, tendo como horizonte uma ética preocupada com a justiça ambiental.

Entretanto, percebe-se que a área de pesquisa em Ensino de Física ainda possui um longo caminho a percorrer no tratamento educativo de aspectos da temática ambiental. Do ponto de vista quantitativo, se for considerado o total de trabalhos apresentados nos EPEF, ainda é pequeno o número de artigos que abordam diferentes aspectos da temática ambiental. Na perspectiva qualitativa, entende-se que os trabalhos podem avançar nas análises sobre alguns aspectos básicos relacionados às práticas educacionais voltadas para a temática ambiental, destacando que

[...] o desenvolvimento de propostas educacionais relacionadas com a temática ambiental coloca-nos diante de uma dupla tarefa, que pode ser entendida como se fosse um trabalho de identificação das duas faces de uma mesma moeda: a necessidade da clareza quanto às perspectivas, tanto em relação ao processo educativo quanto em relação à temática ambiental. Que pressupostos são eleitos para orientar as reflexões, para ancorar as simbolizações ou que justificam as decisões políticas diante da temática ambiental e do processo educativo? Que dimensões da existência humana se pretende considerar nos projetos de educação ambiental? (CARVALHO, 2006, p. 22).

Carvalho (2006) apresenta a necessidade de serem abarcadas nas considerações sobre a temática ambiental e o processo educativo três dimensões da realidade constituintes da práxis humana: 
1 - a dimensão relacionada à natureza dos conhecimentos; 2 - a dimensão axiológica de nossa existência, isto é, relacionada com os valores éticos e estéticos, 3 - o tratamento dado às possibilidades de participação política do indivíduo, tendo como meta a formação de cidadãos e a construção de uma sociedade democrática. (CARVALHO, 2006, p. 26, grifos do autor)

De acordo com o autor, deve-se evitar a possibilidade de que essas dimensões sejam tratadas de forma isolada ou que uma delas seja enfatizada em detrimento das demais.

\section{CONSIDERAC̣ÕES FINAIS}

Esta investigação apresenta uma análise dos trabalhos divulgados nas atas das edições do EPEF realizadas no período de 2000 a 2012 que abordam a temática ambiental e/ou a articulação desta com o processo educativo.

Considerando o relevante papel da Física para a compreensão de diferentes aspectos da temática ambiental, chama a atenção o fato de existirem poucos trabalhos voltados para a discussão e a articulação da temática ambiental e o processo educativo. Portanto, considera-se que ainda são limitados os estudos que relacionam a temática ambiental e o processo educativo no campo do Ensino de Física.

É possível que essa lacuna possa estar articulada com a história da Física escolar, ainda marcada por uma vinculação a uma abordagem quase que exclusivamente conceitual. Nessa perspectiva, a temática ambiental ainda permanece marginal na abordagem tradicional da Física. Este deveria ser um item de maior atenção voltado para toda a comunidade de Ensino de Física, sobretudo ao se considerar que os problemas socioambientais ganham cada vez mais importância e urgência na sociedade contemporânea.

Todavia, deve-se enfatizar que a incorporação da temática ambiental no Ensino de Física deve se dar, também, pela promoção da problematização dos valores que sustentam a cultura capitalista, sobretudo sua lógica centrada no individualismo e no consumismo. Além disso, o tratamento dos temas socioambientais implica no rompimento das fronteiras disciplinares.

De modo geral, a análise do corpus documental indica que prevalecem, entre os trabalhos investigados, considerações mais próximas de uma perspectiva crítica e emancipadora em relação ao processo educativo. No entanto, ressalta-se novamente que $47 \%$ dos trabalhos analisados pertencem a dois grupos de pesquisa.

Para finalizar, em uma perspectiva de continuidade, alguns aspectos necessitam de maior aprofundamento, como é o caso das possíveis aproximações entre pressupostos da Educação Ambiental e do campo CTS/CTSA em trabalhos da área de Ensino de Física. Ou, ainda, trabalhos que investiguem as dimensões da realidade que poderiam ser eleitas como estruturadoras de atividades educativas relacionadas com a temática ambiental na área de Ensino de Física em uma perspectiva crítica e emancipadora. 


\section{NOTAS}

${ }^{1}$ Nos quais a temática ambiental e/ou a temática ambiental e o processo educativo, também, não eram foco central das análises.

${ }^{2}$ Cf. SILVA, 2007.

\section{REFERÊNCIAS}

BARDIN, L. Análise de conteúdo. 5 ed. Lisboa: Edições 70, 2009. 281 p.

BORHEIM, G. Filosofia e política ecológica. Revista Filosófica Brasileira, Rio de Janeiro, v. 1, n. 2, p. 16-24, 1995.

CARVALHO, I. C. M. Educação ambiental crítica: nomes e endereçamentos da educação. In: LAYRARGUES, P. P. (Org.) Identidades da educação ambiental brasileira / Ministério do Meio Ambiente. Diretoria de Educação Ambiental. Brasília: Ministério do Meio Ambiente, 2004.

CARVALHO, I. C. M. Educação ambiental: a formação do sujeito ecológico. 5. ed. São Paulo: Cortez Editora, 2011.

CARVALHO, L. M. A temática ambiental e a escola de primeiro grau. 1989. 287 f. Tese (Doutorado em Educação) - Universidade de São Paulo, São Paulo, 1989.

CARVALHO, L. M. A temática ambiental e o processo educativo: dimensões e abordagens. In: CINQUETTI, H. S.; LOGAREZZI, A. (Org.). Consumo e resíduos: fundamentos para o trabalho educativo. São Carlos: EdUFSCAR, 2006. p. 19-41.

LAVILLE, C.; DIONNE, J. A construção do saber: manual de metodologia da pesquisa em ciências humanas. Porto Alegre: Artmed; Belo Horizonte: UFMG, 1999.

LEFF, H. Epistemologia Ambiental. São Paulo: Cortez, 2002.

LIMA, G. F. C. Educação e sustentabilidade: Possibilidades e falácias de um discurso. In: ENCONTRO DA ASSOCIAÇÃO DE PÓS-GRADUAÇÃO E PESQUISA EM AMBIENTE E SOCIEDADE, 1., 2002. Anais..., Indaiatuba: ANPPAS, 2002.

LORENZETTI, L; DELIZOICOV, D. Estilos de pensamento em educação ambiental: uma análise a partir das dissertações e teses. In: ENCONTRO DE PESQUISA EM ENSINO DE FÍSICA, 7., 2009. Atas... Florianópolis: SBF, 2009.

MacLEOD, K. L. Integrating Science, Technology, Society and Environment (STSE) into Physics Teacher Education: pre-service teachers'perceptions and challenges. 2012. 225 p. Doctoral Thesis (Doctoral in Philosophy) - Departament of Curriculum Teaching and Learning-Ontario Institute for Studies in Education of the University of Toronto, Toronto, 2012.

MARTINS, I.; FERNANDES, J. P.; ABREU, T. B. Uma análise qualitativa e quantitativa da produção científica sobre CTS (Ciência, Tecnologia e Sociedade) em atas do Encontro de Pesquisa em Ensino de Física no período de 1998 a 2008. In: ENCONTRO DE PESQUISA EM ENSINO DE FÍSICA, 12., 2010. Atas... Águas de Lindóia: SBF, 2010. 
MORAES, A. C. R. Meio ambiente e ciências humanas. São Paulo: Hucitec, 2002.

OLIVEIRA, E.; ENS, R. T.; ANDRADE, D. B. S. F.; MUSSI, C.R. Análise de Conteúdo e Pesquisa na Área da Educação. Rev. Diálogo Educacional, Curitiba, v. 4, n. 9, p. 11-27, maio/ago. 2003.

RIBEIRO, R. A.; KAWAMURA, M. R. D. Educação ambiental e temas controversos. Rev. Bras. de Pesq. em Ed. em Ciências, São Paulo, v. 14, n. 2, p. 159-169, 2014.

SANTOS, W. L. P.; CARVALHO, L. M.; LEVINSON, R. A dimensão política da educação ambiental em investigações de revistas brasileiras de ensino de ciências. Rev. Bras. de Pesq. em Ed. em Ciências, São Paulo, v. 14, n. 2, p. 199-213, 2014.

SILVA, L. F. A temática ambiental, o processo educativo e os temas controversos: implicações teóricas e práticas para o ensino de Física. 2007. 211 f. Tese (Doutorado em Educação) - Universidade do Estado de São Paulo, Araraquara, 2007.

STRIEDER, R. B.; KAWAMURA, M. R. Panorama das pesquisas pautadas por abordagens CTS. In: ENCONTRO NACIONAL DE PESQUISA EM EDUCAÇÃO EM CIÊNCIAS, 7., Florianópolis, 2009. Atas eletrônicas... Florianópolis: ABRAPEC, 2009. Disponível em: < http://posgrad.fae.ufmg.br/posgrad/ viienpec/pdfs/463.pdf> Acesso em 27/10/2013.

WATANABE-CARAMELLO, G. Aspectos da complexidade: contribuições da Física para a compreensão do tema ambiental. 2012. 246p. Tese (Doutorado) -Instituto de Física e Química e Faculdade de Educação, Universidade de São Paulo, São Paulo, 2012.

WATANABE-CARAMELLO, G.; KAWAMURA, M. R. D. Uma educação na perspectiva ambiental crítica, complexa e reflexiva. Rev. Bras. de Pesq. em Ed. em Ciências, São Paulo, v. 14, n. 2, p. 255-264, 2014.

\section{REFERÊNCIAS CORPUS DOCUMENTAL}

ALVES, J. A. P.; MION, R. A.; CARVALHO, W. L. P. de. Formação de professores de Física e implicações da relação ciência, tecnologia, sociedade e ambiente: possibilidades, desafios e limitações. In: ENCONTRO DE PESQUISA EM ENSINO DE FÍSICA, 11., Curitiba, 2008. Atas eletrônicas... Curitiba: SBF, 2008. Disponível em: <http://www.sbf1.sbfisica.org.br/eventos/epef/xi/sys/resumos/T0079-2.pdf $>$. Acesso em: 20 out. 2013.

ASSIS JUNIOR, A.; ASSIS, A.; CARVALHO, F. L.C. Física e meio ambiente no ensino fundamental: possibilidades, desafios e limitações. In: ENCONTRO DE PESQUISA EM ENSINO DE FÍSICA, 11., Curitiba, 2008. Atas eletrônicas... Curitiba: SBF, 2008. Disponível em: <http://www.sbf1.sbfisica.org.br/eventos/ epef/xi/sys/resumos/T0125-3.pdf>. Acesso em: 20 out. 2013.

BASTOS FILHO, J. B. Um breve ensaio sobre eventuais contribuições da Física para o estudo de questões educacionais, ambientais e de desenvolvimento. In: 
ENCONTRO DE PESQUISA EM ENSINO DE FÍSICA, 7., Florianópolis, 2000. Atas eletrônicas... Florianópolis: SBF, 2000. CD-ROM.

BENJAMIN, A. A.; TEIXEIRA, O. P. B. Análise de um texto paradidático sobre energia e meio ambiente. In: ENCONTRO DE PESQUISA EM ENSINO DE FÍSICA, 7., Florianópolis, 2000. Atas eletrônicas... Florianópolis: SBF, 2000. CD-ROM.

BERNARDO, J. R. R.; VIANNA, D. M.; FONTOURA, H. A. da. Construção de estratégias pedagógicas em ciência-tecnologia-sociedade (CTS) para a formação de professores: a energia elétrica na sala de aula. In: ENCONTRO DE PESQUISA EM ENSINO DE FÍSICA, 11., Curitiba, 2008. Atas eletrônicas... Curitiba: SBF, 2008. Disponível em: < http://www.sbf1.sbfisica.org.br/eventos/epef/ xi/sys/resumos/T0282-1.pdf>. Acesso em 20 out. 2013.

LIMA NETO, J. A.; BARRETO, C. L. O uso da abordagem CTSA no ensino de energia tendo o desenvolvimento sustentável como eixo temático. In: ENCONTRO DE PESQUISA EM ENSINO DE FÍSICA, 14., Maresias, 2012. Atas eletrônicas... Maresias: SBF, 2012. Disponível em: <http://www.sbf1.sbfisica.org.br/ eventos/epef/xiv/sys/resumos/T0311-1.pdf>. Acesso em 20 out. 2013.

PRESTES, R. F.; SILVA, A. M. M. O ciclo dialético questionamento-argumentação-comunicação em uma proposta de estudo das questões energéticas na sala de aula de Física. In: ENCONTRO DE PESQUISA EM ENSINO DE FÍSICA, 11., Curitiba, 2008. Atas eletrônicas... Curitiba: SBF, 2008. Disponível em: <http://www.sbf1.sbfisica.org.br/eventos/epef/xi/sys/resumos/T0202-1. pdf $>$. Acesso em: 20 out. 2013

REIS, D. A.; SILVA, L. F.; SILVA, A. P. Futuros professores de física e a compreensão sobre o tema mudanças climáticas. In: ENCONTRO DE PESQUISA EM ENSINO DE FÍSICA, 12., Águas de Lindóia, 2010. Atas eletrônicas... Águas de Lindóia: SBF, 2010. Disponível em: < http://www.sbf1.sbfisica.org.br/eventos/epef/xii/sys/resumos/T0095-2.pdf >. Acesso em: 20 out. 2013.

SANTOS, A. G.; BARROS, F. S. Abordagem do aquecimento global em livros didáticos de física do ensino médio. In: ENCONTRO DE PESQUISA EM ENSINO DE FÍSICA, 12., Águas de Lindóia, 2010. Atas eletrônicas... Águas de Lindóia: SBF, 2010. Disponível em: <http://www.sbf1.sbfisica.org.br/eventos/ epef/xii/sys/resumos/T0162-1.pdf >. Acesso em: 20 out. 2013.

SANTOS, L. C. A.; KAWAMURA, M. R. D. O meio ambiente e o ensino de Física. In: ENCONTRO DE PESQUISA EM ENSINO DE FÍSICA, 7., Florianópolis, 2000. Atas eletrônicas... Florianópolis: SBF, 2000. CD-ROM.

SILVA, L. F.; CARVALHO, L. M. O ensino de Física e a temática ambiental: a produção de energia elétrica em larga escala como um tema controverso. In: ENCONTRO DE PESQUISA EM ENSINO DE FÍSICA, 10., Londrina, 2006. Atas eletrônicas... Londrina: SBF, 2006. CD-ROM.

- Professores de Física em formação inicial: o ensino de Física, a temática ambiental e os temas controversos. In: ENCONTRO DE PESQUISA EM ENSINO DE FÍSICA, 11., Curitiba, 2008. Atas eletrônicas... Curitiba: SBF, 2008. 
Disponível em: <http://www.sbf1.sbfisica.org.br/eventos/epef/xi/sys/resumos/T0089-1.pdf>. Acesso em: 20 out. 2013.

- A compreensão dos alunos do ensino médio quanto ao tema produção de energia elétrica em larga escala. In: ENCONTRO DE PESQUISA EM ENSINO DE FÍSICA, 8., Águas de Lindóia, 2002. Atas eletrônicas... Águas de Lindóia: SBF, 2002. CD-ROM.

- A temática ambiental e o ensino de Física na escola média: avaliação do posicionamento dos alunos em relação a aspectos controversos. In: ENCONTRO DE PESQUISA EM ENSINO DE FISICA, 9., Jaboticatubas, 2004. Atas eletrônicas... Jaboticatubas: SBF, 2004. CD-ROM.

SOUSA, P. F. F.; KAWAMURA, M. R. D. Desenvolvimento sustentável e ensino de Física. In: ENCONTRO DE PESQUISA EM ENSINO DE FÍSICA, 9., Jaboticatubas, 2004. Atas eletrônicas... Jaboticatubas: SBF, 2004. CD-ROM.

WATANABE, G., KAWAMURA, M. R. D. Uma abordagem temática para a questão da água. In: ENCONTRO DE PESQUISA EM ENSINO DE FÍSICA, 10., Londrina, 2006. Atas eletrônicas... Londrina: SBF, 2006. CD-ROM.

WATANABE-CARAMELLO, G.; KAWAMURA, M. R. D. Uma abordagem termodinâmica para discutir a física do meio ambiente. In: ENCONTRO DE PESQUISA EM ENSINO DE FÍSICA, 12., Águas de Lindóia, 2010. Atas eletrônicas... Águas de Lindóia: SBF, 2010. Disponível em: < http:/ / www.sbf1.sbfisica.org.br/ eventos/epef/xii/sys/resumos/T0173-1.pdf >. Acesso em: 20 out. 2013.

- Aproximações e contrapontos: complexificação do conhecimento cotidiano e abordagem temática. In: ENCONTRO DE PESQUISA EM ENSINO DE FÍSICA, 14., Maresias, 2012. Atas eletrônicas... Maresias: SBF, 2012. Disponível em: <http://www.sbf1.sbfisica.org.br/eventos/epef/xiv/sys/resumos/ T0350-1.pdf>. Acesso em: 20 out. 2013.

XAVIER, M. E. R.; KERR, A. S. A análise do efeito estufa em textos paradidáticos e periódicos jornalísticos In: ENCONTRO DE PESQUISA EM ENSINO DE FÍSICA, 8., Águas de Lindóia, 2002. Atas eletrônicas... Águas de Lindóia: SBF, 2002. CD-ROM.

\section{Data recebimento: 27/11/2013 \\ Data aprovação: 09/03/2015}

Os autores agradecem 0 apoio do CNPq.

Contato Luciano Fernandes Silva

Rua Luiz Gonzaga Faria, 181

Bairro Pinheirinho - Itajubá - MG - Brasil

CEP: $37500-351$

E-mail: lufesilv@gmail.com 